\title{
ANÁLISE DAS VOGAIS POSTÔNICAS FINAIS [e] e [o] NOS FALANTES DO MUNICÍPIO DE DOUTOR PEDRINHO
}

\author{
THE ANALYSIS OF FINAL POSTTONIC VOWELS [e] AND [o] IN SPEAKERS FROM \\ THE MUNICIPALITY OF DOUTOR PEDRINHO
}

\author{
Morgana Carina Lenzi \\ Mestranda em Lingüística - UFSC \\ Terezinha de Moraes Brenner \\ Docente do Programa de Pós-Graduação em Lingüística - UFSC
}

\begin{abstract}
Resumo
O objetivo desta pesquisa foi analisar a fala dos moradores do Município de Doutor Pedrinho (SC), com foco na realização das vogais postônicas finais [e] e [0]. Para tanto, foi realizada entrevista com moradores daquela cidade, subdivididos em três grupos em relação à faixa etária. A hipótese era a de que tais falantes usariam cinco vogais em posição postônica final, não fazendo alçamento das vogais /e/ e /o/, contrariando a teoria dominante que prevê o alçamento vocálico de tais vogais em contexto átono final de palavra. Foi feita uma revisão teórica acerca das vogais do português brasileiro, com foco nas visões estruturalista e autossegmental. Em seguida, procedeu-se à análise dos dados, chegando-se à conclusão de que, naquela comunidade, em contexto de sílaba postônica final, há cinco vogais.
\end{abstract}

Palavras-chave: Fonologia. Vogais. Posição postônica final.

\begin{abstract}
This study aims at analyzing the speech of the residents of the municipality of Doutor Pedrinho, focusing on the achievement of final vowels in words ending with Poston /e/ and $/ 0 /$. To that end, an interview was conducted with residents of that city, divided into three groups in terms of age. The hypothesis was that these speakers use five vowels in final position pos-tonic in words ending with $/ \mathrm{e} /$ and $/ \mathrm{o} /$, contradicting the dominant theory. It was built on a theoretical basis of vowels in Portuguese, aimed at an interrelationship of visions structuralist and autossegmental, emphasizing the first current. Then, proceeded to the analysis of data, have come to the conclusion that, in that community, in the context of final syllable pos-tonic, there are five vowels.
\end{abstract}

Keywords: Phonology. Vowels. Final position pos-tonic.

\section{INTRODUÇÃO}

Este estudo apresenta uma análise da realização das vogais finais átonas em palavras /e/ e /o/ no português falado no município de Doutor Pedrinho, em Santa Catarina. Os dados foram coletados através de entrevistas com informantes de três faixas etárias: de 8 a 15 anos, de 16 a 40 anos e acima de 40 anos. Essas entrevistas foram realizadas no mês de julho de 2008, e continham informações sobre o município e as atividades que os informantes desenvolviam diariamente. Além disso, foi solicitado aos entrevistados que lessem uma lista com cinco sentenças contendo palavras envolvendo o objeto de 
estudo.e outra lista contendo vinte palavras, sendo dez terminadas em /e/ e outras dez terminadas em /o/ .

Este estudo está amparado na hipótese de que os falantes do Município de Doutor Pedrinho usam cinco vogais em posição final átona. Assim, existiriam palavras pronunciadas com vogais finais átonas /e/ e /o/, contrariando a teoria dominante, que prevê que, nesse contexto, existem apenas três vogais, quais sejam, /a/, /i/ e /u/.

Como exemplos do contexto em exame, têm-se as seguintes palavras:

$$
\begin{array}{ll}
\text { sorvet }[\mathrm{e}] \sim \operatorname{sorvet}[\mathrm{i}] & \operatorname{preferid}[\mathrm{o}] \sim \operatorname{preferid}[\mathrm{u}] \\
\operatorname{dent}[\mathrm{e}] \sim \operatorname{dent}[\mathrm{i}] & \operatorname{menin}[\mathrm{o}] \sim \operatorname{menin}[\mathrm{u}]
\end{array}
$$

A fim de subsidiar a análise, recorreu-se às contribuições de Mattoso Câmara para verificar o que dispõe a visão estruturalista acerca das vogais, bem como às contribuições de Clements, Wetzels e Bisol no que tange à corrente autossegmental. Utilizaram-se também outras contribuições sobre o tema julgadas pertinentes para ampliar o exame pretendido.

De posse do corpus, procedeu-se a uma análise dos fatos fonológicos voltados ao problema e aos objetivos dessa pesquisa, entrecruzando-os com a teoria consultada.

\section{O MUNICÍPIO DE DOUTOR PEDRINHO}

Doutor Pedrinho é uma cidade localizada no Vale do Itajaí, na microrregião de Blumenau, a $200 \mathrm{~km}$ de Florianópolis. Os moradores são descendentes dos colonizadores italianos, na maioria, e alemães, que passaram a habitar a região por volta de 1920.

Os colonizadores italianos que ali se instalaram eram de famílias originárias da região de Vêneto e, principalmente, de Trento, de onde emigrou a maior parte dos italianos que se estabeleceram no Vale do Itajaí, em Santa Catarina.

A população estimada pelo último censo realizado pelo IBGE é de aproximadamente 3.000 habitantes e as atividades econômicas de destaque são a rizicultura e o turismo ecológico, em razão das cachoeiras, grutas e montanhas.

As principais famílias que colonizaram o local ainda possuem descendentes no município, muitos dos quais mantêm vivas algumas tradições, incluindo o uso freqüente de língua estrangeira (alemão e, principalmente, italiano) em conversas no âmbito familiar, bem como nas demais esferas sociais.

\section{AS VOGAIS NA VISÃO ESTRUTURALISTA}

Em seus apontamentos acerca das vogais portuguesas, Câmara Jr. (1977a) afirma que a posição ótima para caracterizar as vogais é a que se forma, de um lado, pela presença de uma particular força expiratória (acento) e, de outro, uma ligeira elevação da voz (tom). É desse modo que se configura a posição tônica, de onde se dá a classificação das vogais como fonemas. 
Ele destaca que há sete vogais no português, partindo-se da posição tônica, as quais se reduzem a cinco em contextos de consoante nasal. Os quadros abaixo representam claramente sua postulação:

(2) Vogais em posição tônica

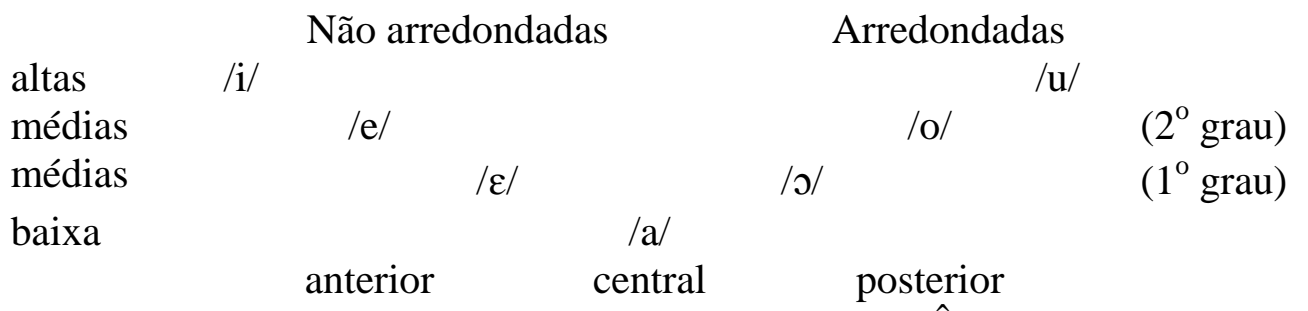

(CÂMARA JR., 1977a, p. 31)

(3) Vogais em posição tônica diante de nasal

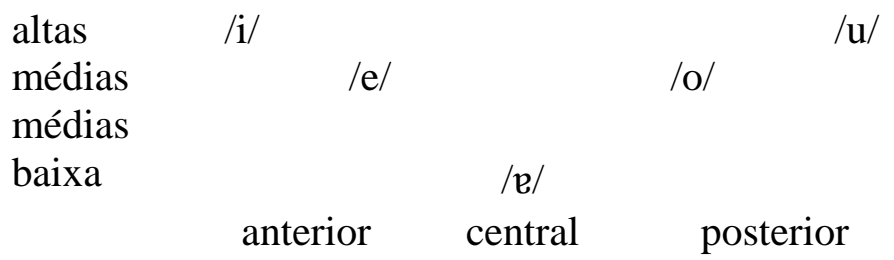

(CÂMARA JR., 1977a, p. 33)

Para as vogais átonas, há significativa mudança, considerando que certas oposições são reduzidas. De acordo com Câmara Jr. (1977b, p. 33):

[...] o que essencialmente caracteriza as posições átonas é a redução do número de fonemas. Isto é, mais de uma oposição desaparece ou se suprime, ficando para cada uma um fonema em vez de dois. É o que Trubetzkoy tornou um conceito clássico em fonologia com o nome de neutralização.

Em decorrência das neutralizações que ocorrem nas posições átonas, o sistema vocálico do português, nesses contextos, pode ser assim representado:

(4) Vogais em posição pretônica

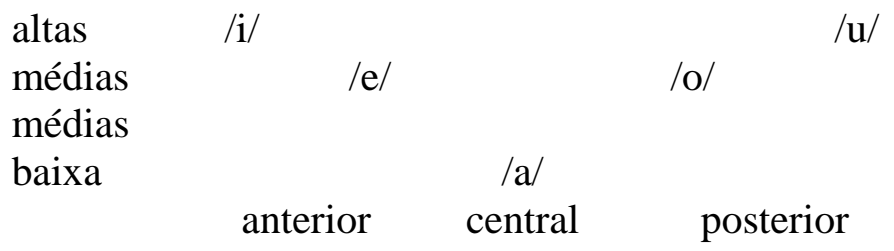

(CÂMARA JR., 1977b, p. 34)

(5) Vogais em posição postônica não-final

$\begin{array}{lccc}\begin{array}{l}\text { altas } \\ \text { médias } \\ \text { médias } \\ \text { baixa }\end{array} & \text { /i } / \mathrm{e} / & & \text { /u/ } \\ & \text { anterior central } & \text { posterior }\end{array}$

(CÂMARA JR., 1977b, p. 34) 
(6) Vogais em posição postônica final

$\begin{array}{llcr}\begin{array}{l}\text { altas } \\ \text { baixa }\end{array} & / \mathrm{i} / & / \mathrm{u} / \\ & \text { anterior } / & \text { central posterior }\end{array}$

(CÂMARA JR., 1977b, p. 34)

É no contexto apresentado em (6) que reside o objeto desta pesquisa. Vê-se que, para Mattoso Câmara, há apenas três vogais nesse contexto, visto que as sílabas átonas finais, seguidas ou não de /S/, são as de maior grau de atonicidade, pois ocorre a neutralização entre as médias.

Câmara Jr. (1977a) reforça a existência de apenas três vogais em posição postônica final, exemplificando com a distinção entre júri e jure ou ânus e anos, que seriam distinções inteiramente gráficas. Ele vai além, apontando que são rimas fonética e fonemicamente perfeitas aquelas que se fazem entre Argus e largos e cálix e vales, o que comprovaria que apesar de serem grafadas com vogais distintas, a pronúncia é a mesma, uma vez que serviriam adequadamente para estabelecer uma rima.

Cumpre mencionar que nos seus estudos Mattoso Câmara aponta como base do português brasileiro a fala de registro formal do dialeto social culto na base da área do país cujo centro é o Rio de Janeiro.

\section{AS VOGAIS NA VISÃO AUTOSSEGMENTAL}

Na visão autossegmental, em que as diferenças de altura são indicadas por meio de traços de abertura, as vogais tônicas podem ser assim apresentadas:

$\begin{array}{lcccc}\text { abertura } & \text { i/u } & \text { e/o } & \varepsilon / 0 & \text { a } \\ & & & & + \\ \text { aberto 1 } & - & - & - & + \\ \text { aberto 2 } & - & + & + & + \\ \text { aberto 3 } & - & - & + & +\end{array}$

(WETZELS, 1992 apud BATTISTI E VIEIRA, 2001, p.169)

De acordo com essa teoria, a distinção entre altas e baixas está ligada a [aberto 3] e há também a constatação de que no contexto de vogal em posição postônica final ocorre a neutralização da distinção entre vogais médias e altas, desassociando [aberto 2], conforme a regra representa apresentada em (8).

Bisol (2003) explica a neutralização proposta por Wetzels da seguinte forma: definidas as vogais em termos da geometria de Clements, com altura vinculada a traços de abertura, aberto 1, aberto 2 e aberto 3, o traço neutralizado é desligado e substituído pelo valor oposto. É por isso que o sistema vai sendo neutralizado, passando de sete vogais, para cinco; depois de cinco para quatro e, finalmente, apenas três vogais. 
(8)

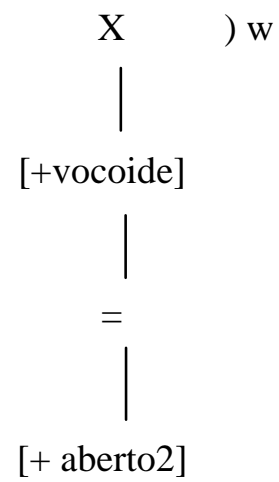

(WETZELS, 1992 apud BATTISTI E VIEIRA, 2001, p.169)

Aplicando para o português o modelo de Clements para os registros de altura vocálica, é possível constatar que nosso idioma se trata de uma língua de registro terciário, apresentando sete vogais; em seguida reduzida a registro secundário, com cinco vogais, no contexto de pretônica e postônico medial; e a registro primário, em átona final, com um subsistema de apenas três vogais.

(9) Registro de altura vocálica do modelo de Clements:

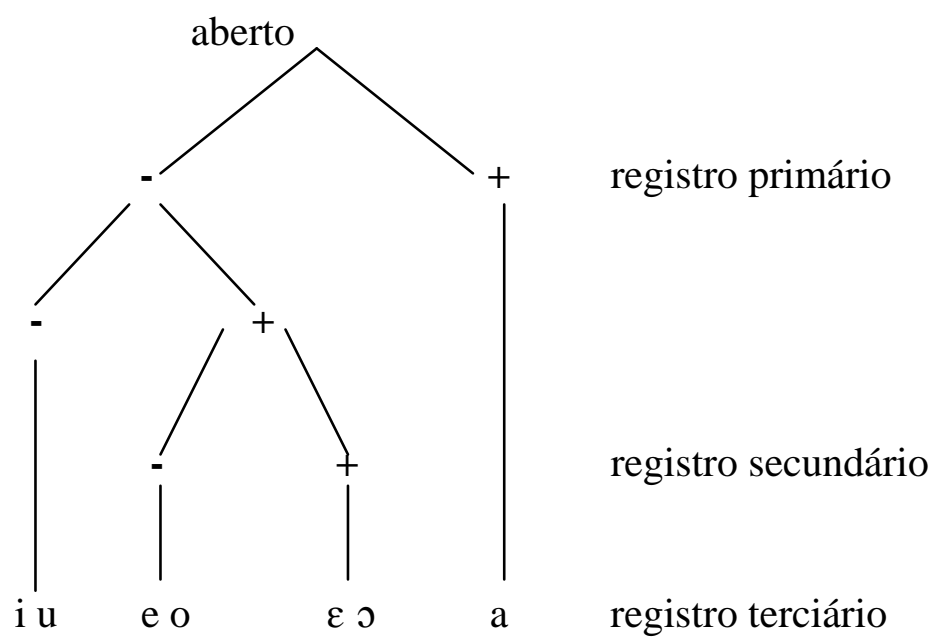

\section{OUTRAS CONTRIBUIÇÕES}

Ferreira Neto (2001), ao discorrer sobre o não reconhecimento, por Mattoso Câmara, das diferenças de grau de abertura entre vogais altas e médias, destaca que em certas regiões do Brasil, tais como vale do Tietê e norte do Paraná, é comum ocorrer a realização das vogais átonas finais [e] e [o].

Para ele, a desconsideração desse fenômeno fonológico está vinculada diretamente ao fato de ser vista como uma pronúncia estigmatizada. Corroborando a validade de um sistema com cinco vogais em posição átona postônica, o Ferreira Neto (2001, p. 118) traz a seguinte hipótese: 
Na medida em que as vogais átonas finais resultam, na sua grande maioria, das formas latinas do acusativo singular com supressão da nasal pós-vocálica $-a(m)>-a,-e(m)>-e,-i(m)>-e$ e $-u(m)>-o$, a exclusividade dessas vogais átonas em posição final no português parece estar historicamente condicionada, não se tratando, pois, de fenômeno de natureza fonológica, mas morfológica.

Conclui Ferreira Neto (2001) que o alçamento vocálico resultou do estabelecimento de um dialeto mais prestigiado, que se consagrou como a pronúncia rotulada como padrão do português.

Outra contribuição muito adequada para a pesquisa ora desenvolvida é o estudo feito por Roveda (1998), cujo título é Elevação da vogal média átona final em comunidades bilíngües: português e italiano. Conferindo os dados, a autora chegou à conclusão de que os metropolitanos (do Rio Grande do Sul e Santa Catarina) aplicaram a regra de elevação em $99 \%$ e 100\% dos casos, respectivamente, podendo se considerar uma regra de aplicação geral, cuja tendência é de tornar-se uma regra categórica. No entanto, os bilíngües, descendentes de italianos, ainda preservam as vogais médias, para o que há várias hipóteses, dentre elas uma nítida interferência do italiano sobre o português. Uma das justificativas seria que, conforme Störig, (1993 apud Roveda, 1998), na língua italiana, assim como no latim,

a maioria dos substantivos terminam em vogal; os masculinos terminam em o e formam plural em -i: l'anno 'o ano'; i gli anni, 'os anos'. Os femininos terminam em -a e formam plural em -e: la corona, 'a coroa'; le corone, 'as coroas'. Caso a palavra termine em -e, o plural é em -i: il fiore, ‘a flor’; i fiori, 'as flores'. (...)

Dardano e Trifone (1996 apud Roveda, 1998) apontam que os falantes de italiano conhecem a regra morfofonológica que transforma e em i, assim como a e 0 .

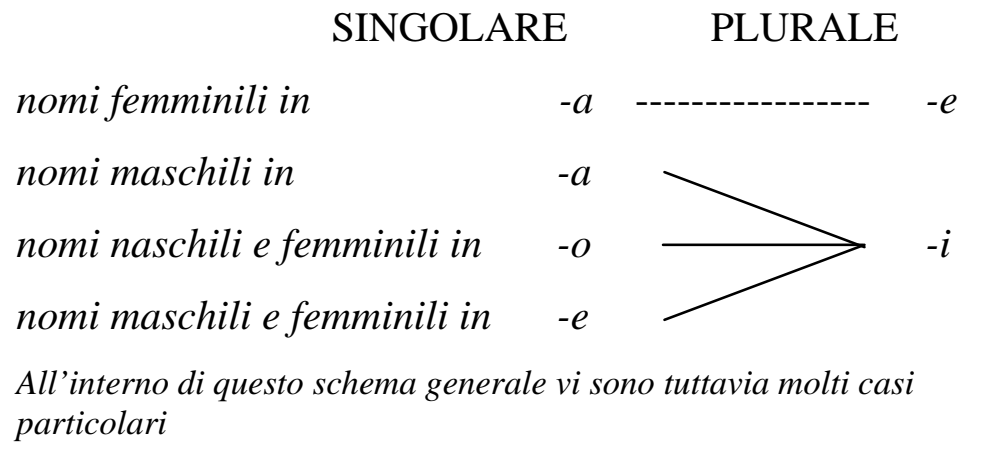

Feitas as verificações dos dados de sua pesquisa envolvendo as vogais em posição postônica final em comunidades bilíngües (português/italiano), Roveda (1998) concluiu que as comunidades bilíngües analisadas ainda exibem bastante a vogal média em posição átona final, o que confirma que o grupo étnico é, entre os fatores estudados, o mais relevante. 


\section{ANÁLISE DOS DADOS}

De posse do corpus coletado em entrevistas conforme exposto anteriormente, chegou-se ao levantamento acerca da realização da vogal final postônica em palavras terminadas em [e] e [o] no português falado no município de Doutor Pedrinho (Tabela 1):

TABELA 1: Idade - Realização das átonas finais [e, o] em Doutor Pedrinho/SC

\begin{tabular}{c|c}
\hline FATOR IDADE & OCORRÊNCIA \\
\hline $8-15$ anos & $85,83 \%$ \\
\hline $16-40$ anos & $91,25 \%$ \\
\hline Acima de 40 anos & $98,33 \%$ \\
\hline
\end{tabular}

Fonte: Do autor

Os dados, apresentados na Tabela 1, apesar da leve tendência de crescimento de casos de alçamento, indicam que, no local onde se procedeu à pesquisa, prevalece o não alçamento vocálico, isto é, as vogais médias não são transformadas em vogais altas. Pela Tabela 1, verifica-se, ainda, que o fator idade não é relevante para estabelecer uma distinção de comportamento em relação ao objeto deste estudo. Sendo assim, pode-se concluir, com relação à visão estruturalista, que os dados desta pesquisa mostram que o quadro de vogais em posição postônica final seria formado por cinco vogais e não apenas três.

Importante repetir aqui que, para Mattoso Câmara, o dialeto de prestígio do Rio de Janeiro era a base, o que permite identificar com mais clareza as possíveis divergências com sua teoria em decorrência do uso de corpus de outra comunidade de fala, como é o caso da utilizada neste estudo. Denota-se, assim, uma diferença marcante entre o dialeto carioca da capital e o dialeto da comunidade do interior de Santa Catarina.

Cotejando os dados com o que estabelece a teoria autossegmental para as vogais, conforme visto em (7), percebe-se que ocorre o mesmo fenômeno, uma vez que, naquela comunidade de fala, o português não se verifica como uma língua de registro primário para contextos de átona final, com um subsistema de apenas três vogais. No município de Doutor Pedrinho, o cenário de vogal átona final utiliza o registro secundário, com cinco vogais, relativo ao contexto de pretônica.

\section{CONCLUSÃO}

Efetuada a análise, concluiu-se que os falantes do município de Doutor Pedrinho usam cinco vogais em posição final postônica em palavras terminadas em /e/ e /o/, contrariando a teoria dominante, a qual prevê que nesse contexto existem apenas três vogais, quais sejam: /a/, /i/ e /u/.

No que tange à teoria estruturalista, os falantes pesquisados fazem uso de um sistema formado por cinco vogais, contrariando o que a corrente de Mattoso Câmara estabelece para esse contexto, o qual seria formado por apenas três vogais. Com relação à teoria autossegmental, o estudo mostrou que o dialeto falado em Doutor Pedrinho é relativo a uma língua de registro secundário, com cinco vogais. 
Apesar de se tratar de um fato estigmatizado, os falantes daquela região ainda sofrem significativa influência histórica, visto se tratar de um reflexo do bilingüismo, sobretudo português/italiano, que marca o dialeto da cidade. Assim, considerando tratar-se de uma comunidade com forte característica italiana, os dados levam a crer que a etnia seja um fator condicionante para a elevação ou não da vogal média em posição átona final.

Pesquisas futuras poderiam, a partir da comparação da fonologia da língua italiana com a portuguesa, detectar se o não alçamento de /e/ e /o/ em contexto de sílaba postônica final deve-se a alguma interferência do italiano na fala de comunidades bilíngües (italiano/português).

Além disso, na perspectiva dos estudos Sociolingüísticos, caberia verificar se o alçamento vocálico poderia é visto como uma variante, porém desprestigiada.

\section{REFERÊNCIAS}

BATTISTI, E.; VIEIRA, M. J. B. O sistema vocálico do português. In: BISOL, L. (Org.) Introdução aos estudos de fonologia do português brasileiro. 3. ed. Porto Alegre: EDIPUCRS, 2001. p. 159-194.

BISOL, Leda. A neutralização das átonas. Revista Letras, Curitiba, n. 61, especial, p.273-283, 2003.

CÂMARA JR., Joaquim Mattoso. Estrutura da língua portuguesa. 8. Ed. Petrópolis: Vozes, 1977a. 1977b.

Para o estudo da fonêmica portuguesa. 2. Ed. Rio de Janeiro: Padrão,

FERREIRA NETTO, Waldemar. Introdução à fonologia da língua portuguesa. São Paulo: Hedra, 2001.

ROVEDA, Suzana Damiani. Elevação da vogal média átona final em comunidades bilíngües: português e italiano. Porto Alegre, 1998. Dissertação (Mestrado), PUC-RS, 1998.

SILVA, Thaïs Cristófaro. Fonética e fonologia do português: roteiro de estudos e guia de exercícios. 8. ed. São Paulo: Contexto, 2005. 